\title{
Knowledge audit as an important tool in organizational management: A review of literature
}

\begin{abstract}
The purpose of this paper is to review current literature on knowledge management and highlight the importance of knowledge audit in bringing about a holistic knowledge solution to knowledge management. Based on the review of literature on knowledge management, this study points out the role of knowledge audit in solving the challenges in organizations' tacit and explicit knowledge. Specifically, the paper concentrates on knowledge audit, knowledge risk and international and national standards on knowledge audit processes.

The contribution of this study to literature are the suggestions that knowledge risk and international standards procedures could be applied to knowledge audit. The important conclusion of this paper is that knowledge risk management has not been fully explored in the study of knowledge audit. The paper addresses the research question of what organizations must embark on in the process of knowledge audit.

The paper attempts to provide answer to the question by highlighting the importance of knowledge audit and the reasons why organizations carry out knowledge audit, and also the existing knowledge audit frameworks and methodologies.
\end{abstract}

\section{Keywords}

Knowledge audit, knowledge audit approach, knowledge management, knowledge risk

\section{Introduction}

The literature on knowledge management supports the role of knowledge as an invaluable tool for organizations (BouLlusar and Segarra-Cipres, 2006). Bou-Llusar and Segarra-Cipres highlighted two distinct views on knowledge (1) competitive advantages benefits are derived from knowledge, and (2) the creation of core competencies in an organization derives from the proper utilization of knowledge. This study proposes to analyze the importance of knowledge audit in organizational management. The paper is organized in the following order. The first section addresses the types of knowledge. The second section focuses on knowledge management. In the third section, we address the implication of knowledge audit as an important tool of organizational management. The final section proposes a theoretical framework for examining knowledge risks, and international and national standards related to knowledge audit processes.

\section{Knowledge}

The world is going through a global transformation from agricultural economy, industrial economy to knowledge economy, which asserts that knowledge is one of the main factor in production (LaFayette et al., 2019). Knowledge economy has transformed organizations, various departments, and the working environment. It has moved employees from physical walls in offices to virtual offices where employees can work from home. It has transformed the human resources department from managing employee job roles to managing their capacities and capabilities (LaFayette et al., 2019). All organizations are turning into knowledge organization, where they need data, information and knowledge to achieve their organizational objectives. 
Knowledge is accumulation of information that is acquired, processed, refined, and used to achieve the organizational objectives or that add value to the organization and used for executing strategic decisions. Knowledge is a critical resource for organizations that compete in unpredictable and fast-changing environments (Levallet and Chan, 2016) and also organization needs innovation to survive in turbulent time, as knowledge is one of the main input in innovation and the management of the knowledge is very important (Temel and Vanhaverbeke, 2020). Example of knowledge asset are the capital knowledge, intellectual knowledge, flowcharts, inventories, subject-specific techniques, methods, skills and algorithms personal data rights and patent and copyright laws organizational repositories, project documentation and operational IT systems. To maintain core competency in organization, maintaining and organizing knowledge should be utmost prior (Metaxiotis et al., 2005).

Knowledge is the information in human's mind or experience and understanding of humans (Marwick, 2001) and consists of expertise, skills and information (Anand and Walsh, 2016). It also consists of information that is readily available and can be utilized to make decisions and influence actions (Chang and Lin, 2015). In today's world when organization has large volume of knowledge asset, there is need to evaluate or scruntize the knowledge bank or asset in order to provide effective feedback based on the organization's knowledge management, improve the relevance, effectiveness, efficiency, and sustainability of ongoing and future organization which will inturn assist in achieving the organization goals.

\section{Characteristics of knowledge}

The new economy is the data and knowledge-based economy which knowledge is divided into tacit and explicit knowledge (Gourlay, 2002). According to the Nonaka (1991), the identification of the types of knowledge has centered around explicit knowledge and tacit knowledge. Explicit knowledge is defined as 'the knowledge that is transferable in a formal and systematic way, by means of a language, since it can be easily articulated and interchanged, because it is independent of the individual's mind' (p. 2). Nonaka (1991) viewed explicit knowledge as a knowledge that is formal and systematic, and expressed in words and symbols which can be communicated via computer programs, product specifications and scientific formulas. Mearns and Du Toit (2008) averred that explicit knowledge can be stored and recorded in artifacts, can be printed in electronic and audiovisual ways.

Explicit knowledge are knowledge that are in codified form used to achieve the organizational goals while explicit knowledge are knowledge that are not codified, that is still raw in the head of the employees which it is used to achieve the organizational objectives. The world is having an overload or overflow of data, information or knowledge; it is becoming difficult for organization to streamline or evaluate large amount of data, information, and knowledge to achieve the organization objective and also one of the challenges of employees in the organization is the willingness to share information among employees; while some hide these knowledged because they are scared of sharing it in order not to loose superiority at work place. These tacit knowledge are hoarded for fellow employees, or if an employee leaves the organization and such employees might share vital data, information and knowledge of the organization to competitors which will later affect the functionalities or profitability of the organization. Moreso, the demise of the employee hoarding this knowledge might be an issue whereby none in the organization could do the task the person is doing. There are a lot of risk attached to both explicit and implicit knowledge which can be solved with the provision of good and sound knowledge audit strategy. 
Perez-Soltero et al. (2006) defined tacit knowledge as the knowledge possessed by an individual and domiciled in his or her experiences with individual features and quality that makes it difficult to communicate or formalize. The experience inherent in tacit knowledge can be communicated or transferred in effective and direct way via the process of socialization (Nonaka and Takeuchi, 1995). Mearns and Du Toit (2008) viewed tacit knowledge as 'highly personal, informal, involves personal beliefs, values, intuition and insight' (p. 161). Kaniki and Mpahlele (2002) opined that tacit knowledge is unscientific and informal due to its difficulty in codification, but it is direct and transferred from one person to the other via word of mouth. Tacit knowledge is characterized by its inability to be codified and difficulty for communication to exist in stated form. Explicit knowledge on the other hand is characterized by its ability to be codified and ease of transfer to others (Nonaka and Peltokorpi, 2006). Tacit knowledge is the type of knowledge people keep in their minds and it is difficult for others to use (Davenport and Prusak, 1998). To maintain core competency in organization, maintaining and organizing knowledge should be utmost priority (Metaxiotis et al., 2005).

\section{Knowledge management}

Studies on knowledge management (KM) has progressed extraordinarily (Costa and Monteiro, 2016; Kianto and Andreeva, 2014; Kianto et al., 2019). It is presently one of the vigorously studied and hottest topics in management literature due to three considerations. First, the increasing utilization of knowledge in enterprises added to the development of the theory of KM (Aranda and Molina-Fern'andez, 2002). Second, KM is an important area whereby the know-how of attributes in accelerating effective management and governance is non-existent or lacking. Third, KM acts as a key value driver for diversified kinds of organizations (Kianto and Andreeva, 2014).

The review of extant studies indicates that the investigation into knowledge management processes has concentrated on five essential dimensions which include: knowledge retention, knowledge acquisition, knowledge codification, knowledge creation, and knowledge sharing (AlAlawi et al., 2007; Kianto et al., 2018). The academic contributions from KM suggests a focus on two components of KM which are KM practices and KM processes. The knowledge management practices 'is the set of intentional organizational and managerial activities that are aimed at enhancing knowledge processes of the firm' (Kianto and Andreeva, 2014, p. 222). KM processes focuses on the movements of knowledge and procedures of employing expertise in an organization (Alavi and Leidner, 2001). Several studies on KM have proceeded in expressing the mastery of the concept of KM and showcasing its management function in organizations (Andreeva and Sergeeva, 2016).

\section{Definition of knowledge management}

The development of KM could be traced to the 1980s and 1990s (Ruggles, 1998). He also went further to state that knowledge management teaches organizations methods of doing things to create value. Managers are responsible for ensuring the smooth coordination of human and material resources in the organization with a holistic view of achieving stated organizational objectives. In the view of Abubakar et al. (2019), the managerial role of achieving organizational objectives requires adequate knowledge management as well as an excellent decision-making skill. Abusweilem and Abualoush (2019) has explained that KM is evolving as an innovative method of shifting away from traditional method of record and information management; enabling better management and organization of workflow processes. KM refers to the accomplishment of the goals of the organization by making the component knowledge rewarding (Rozman et al., 2019). 
It is also the activities engaged in such as capturing, using and sharing knowledge to help an organization achieve competitive advantage (RingelBickelmaier and Ringel, 2010; Yeh et al., 2006). KM is described as the processes of 'acquiring, converting, applying, and protecting knowledge to improve firms' competitiveness' (Lin, 2007, p. 643). KM is the act of 'selectively using knowledge gathered from previous decision-making experiences to current and future decision making' with the aim of enhancing firm's effectiveness (Jennex and Olfman, 2005). KM is the process of acquiring, storing, sharing and using knowledge (Leidner et al., 2006). It is the ability to manage knowledge. For instance, capturing knowledge, transforming the knowledge to a novel idea, using and saving the knowledge (Gold et al., 2001). KM is the systematic, explicit and use of knowledge that will aid organizations to optimize knowledge-based effectiveness from knowledge properties (Lytras et al., 2002). The objective of KM is for organizations to know the knowledge they have and modify the knowledge for efficient and effective application of such knowledge (Newell et al., 2004). Generally, KM comprises of processes of knowledge such as knowledge creation, knowledge sharing, knowledge transfer, and it function in combination with the arrangements, capacities, and management endeavors that reinforce and sustain knowledge processes (Kianto et al., 2018; Lee and Choi, 2003). The KM literature has shown the diverse classifications of KM practices.

KM practices refer to organizational aspects which can be manipulated and controlled by conscious and planned management activities (Susanty et al., 2018). KM practices on the other hand is the integration of technologies, mechanism and activities that are designed to aid the proper management of knowledge resource in any establishment (Wamuyu and Ndiege, 2018). KM practices enables business to assign usefulness to inputs of its knowledge repository. Shropshire et al. (2019) explains that KM practice is an essential strategy for those seeking to strengthen their value, to improve operations and services, and to inform decisions about investment in resources which if properly executed, it can also serve as enablers of creativity and innovation. Hence, KM practices is the integral factor for organizational learning (Elhachemi, 2020).

KM practices plays an important role in creating new knowledge in the process of sustainable innovation and competitive advantage. Abusweilem and Abualoush (2019) believes that KM practice is a source of excellence and a basis for organizational success and advancement, KM practice has equally emerged as a major catalyst for economic progression and technological advancement. Thus, in order to cope in this dynamic business environment, there is need to accelerate speed and ability in making/implementing decisions; which is attached to KM practices.

Abubakar et al. (2019) asserts that knowledge management practices aid the clear understanding of information, decision-making and ultimately propels organizational performance. Meher and Mishra (2019) explained that the performance of businesses are attributed to its innovation capabilities aided by efficient use of knowledge personnel. Thus, competitive advantage is increasingly based on the successful utilization, leverage and creation of KM practice (El-Farr and Hosseingholizadeh, 2019). Kianto and Andreeva (2014) organize KM practices into knowledge management strategy, human resources management practices, organizational culture, ICT tools, and organizational design. This study shall align with the identification of KM processes found in the studies of (Kianto et al., 2018) which include five dominant classification.

Knowledge acquisition: The existing literature suggests that outside networks and concerted efforts are vital sources of knowledge for different organizations. Knowledge acquisition refers to the practices in an organization targeted at gathering information from additional organizational sources. 
Knowledge sharing: Another classification of KM processes is knowledge sharing. This involves implied knowledge immersed in the experiences of human beings and shared via communal interaction (Kianto et al., 2018). It is also explained in the literature that organizations should encourage regular interactive communication in building a culture of knowledge sharing.

Knowledge creation: A third classification of KM processes is knowledge creation. This pertains to the capacity of an organization to advance new solutions and ideas and bring about innovation to the levels operating in the organization (Kianto and Andreeva, 2014; Kianto et al., 2018). According to Nisula et al. (2019), it is a key significant capability for a firm desirous to accomplish greatness in the highly competitive business environment.

Knowledge codification: A fourth classification of KM processes is the codification of knowledge, which refers to storage of documented information, and made available to employees of an organization to increase their knowledge base and motivate them to be equipped with the technological tools to facilitate knowledge inquisitiveness and transfer of knowledge.

Knowledge retention: The fifth and last classification of KM processes in this study is knowledge retention. Organization are faced with the challenge of attracting and retaining the best employees in this knowledge era. Knowledge retention focuses on actions related to the management of employee turnover and the attendant loss of specialist knowledge.

Various studies on $\mathrm{KM}$ asserted that successful $\mathrm{KM}$ processes helps to gain and maintain competitive advantages (Anantatmula and Kanungo, 2010); KM deals with how best to leverage knowledge both internally and externally in organizations to improve decision-making and facilitate knowledge capture and sharing. It is a critical part of an organization's fabric, and can be used to increase innovation, improve organization internal and external effectiveness, build the institutional memory, and enhance organizational agility (Liebowitz, 2016). However, KM initiatives have failed in the past years and such discussion has been established among knowledge professionals and academia (Braganza and Mo"llenkramer, 2002; Hylton, 2002a; Storey and Barnett, 2000). Liebowitz (2001) asserted that KM fails due to the fact that there is no alignment between KM strategy and organization mission, top management not supporting the KM initiative, which led to the poor design of KM program. Hylton (2002) also explained that unclear clear objectives, unstandardized communication channels are causes of KM failures. Malhotra (2003) identified KM failures based on inadequacy of KM program. Due to the misunderstanding of KM; 84 percent of KM intiatiation and programs failed worldwide due to the fact that organization could not manage large numbers of challenges affecting the success of knowledge management implementation (Alhamoudi, 2010). Cegarra-Navarro, Soto-Acosta, \& Wensley, (2016) further explained that the failure of KM resulted into incomplete knowledge or incorrect, incoherent approach to knowledge elicitation He also identified other challenges identified in literature such as trust, ownership of knowledge, management of digital assets and the maintenance of knowledge. Prior to KM initiatives, it is advisable to do knowledge audit. It was argued that the omission of knowledge audit contributed to the failure of the KM initiatives and implementation; the rate of KM initiatives and programs failure could be reduced with the adaptation of knowledge audit (Cheung et al., 2007; Gourova et al., 2009; Hylton, 2002; Liebowitz et al., 2000; Shukor et al., 2013). They also agreed that KA should be launched before KM initiatives take place.

\section{Definition of knowledge audit}

Knowledge audit (KA) is an important tool in achieving organizational objectives. Also a lot of risk exist in a knowledge economy, knowledge risk need to be evaluated in an organization and an effective tool used for this is knowledge audit. Cheung et al. (2007) opined that in order for an 
organization to evaluate knowledge asset, the organization needs to identify the source, usability, and creation of the knowledge asset in an organization. That is why there is need for periodic evaluation of units, departments and organizations to see which of the processes or procedures that are not documented, which skills needs to be documented, to evaluate the knowledge assets, knowledge asset risk, to see the availability, accessibility and affordability of the knowledge asset and also where there are gaps in knowledge assets, duplications within and among departments and how they could harmonize duplications in order to achieve organizational objectives effectively and efficiently. Serrat (2017) asserted that about 80 percent of an organization's knowledge is still in tacit; the challenge is auditing that to achieve organizational objectives. Therefore, organization needs to intensify in the efforts in developing knowledge auditing strategies in order to fight this cancerworn that has eaten deep in organizations.

Knowledge audit is an important tool for knowledge asset extraction and processing and nurturing. Cheung et al., (2007) asserted that conducting a knowledge audit to identify and evaluates that the present state of knowledge inventories and usagable among and within the organization is needed. Also Sharma et al., (2008) asserted that there is no adequate measure for the successful execution of KM intiaitve; a working solution is the KA and also they claimed that KM lifecycle impacted by the organization of intellectual capital into corporate taxonomy or at the least a knowledge map which can be achieved via knowledge audit. A knowledge audit has long been regarded as the first crucial step in the knowledge management (KM) journey (Choy et al., 2004; Henczel, 2001; Liebowitz et al., 2000; Tiwana, 2002). When carrying out KA; knowledge, data, information, internal and external environment, organization culture and values, organization policies, organizational politics should be taken in consideration. KA output assist organizations to recommend the best KM strategy which is used to manage knowledge better (Shukor et al., 2013).

Scholars in the past has given different definitions on KA based on their various fields; KA is applicable to all field such as finance, data science, information science, engineering, library science etc because all disciplines are moving into data and knowledge economy. Debenham and Clark (1994) defined KA as resource that organization used to identify both hiding and unhiding in order to gain competitive advantage. Liebowitz (1999) defined KA as a qualitative assessment of the state of the knowledge health of an organization. KA identifies major knowledge, information needs and exploit it to maximum in an organization. It scruntizes systematically and review adequately, the integrity of vital knowledge assets and systems in order to see that there are gaps, inadequacies and duplications. Knowledge audit will solve the problem of what knowledge organization have, what is missing, who needs the knowledge and how to use the knowledge to add value to the organizational objectives (Liebowitz, 1999).

Liebowitz et al. (2000) defined KA as the process that clarifies, interactions, gaps, flows and how they impact on business objective. KA is the evaluation of knowledge management process, is the review of the organizational assets when it comes to knowledge and anything in conjunction of knowledge management systems. KA is a systematic test, examining and evaluating of tacit and explicit knowledge resources in an organization (Hylton, 2002). Knowledge audit is defined as KM activity which investigates and analyzes organizational knowledge states and mechanism, reports the knowledge gap of organization according to the knowledge need of organization ( $\mathrm{Wu}$ and $\mathrm{Li}, 2008$ ).

KA was viewed from that aspect of what information is in the organization and where it can be found, knowledge of the expert in handling, maintaining and sustaining knowledge asset in the organization, identify expertise outside the organization and how they could work with the 
organization to achieve the organization objectives, best sources that are germane to external and internal information and knowledge. KA is done in order to evaluate to find out results achieved, what to improved on, identifies various policies, strategies, ethics, programs and projects in an knowledge economy or environment. Hylton (2002b) affirmed that knowledge audit is the first step in effective knowledge management and corporate knowledge valuation. He went further to emphasize that intangible assets cannot be quantified, measured and valued easily. He sees knowledge as intangible assets in organization. Lateef and Omotayo (2019) affirmed that data, information and knowledge are tangible assets in the organization such as other factors of production, such as land, labor and capital which can quanitified, measured and valued. Knowledge audit identifies the strength, weakness, opportunities and threats in terms of corporate knowledge existing in an organization. It investigates, diagnose, analyzes the current corporate knowledge, and identifies the gaps in the corporate knowledge and provide future solutions to the knowledge gaps in order to achieve the organizational objectives and also add value to the organization. It also provides reports which are used to justify whether there is maximum utilization of corportate knowledge valuation.

KA can impact organization performance by evaluating the knowledge assets organization posses which can bring about competitive over competitor, increase sales and profit and provide strategic information for decisionmaking. Social network analysis maps visualize nonformal relationships. KA standardized and visualized the social network analysis mapping to identify and establish the number of people that like or disliking the organization's brands, product, pages and also comments on social media which assist in bring customer's opinions or comment directly and closer to the organization; also help organization to know what the customer needs via the use of social network such as Facebook, Twitter, Instagram, and LinkedIn. It is very fast and cost effective. It shows how staffs seek knowledge, and how they share knowledge among themselves.

\section{Why do organization carry out $K A$}

(a) KA turns tacit knowledge into explicit knowledge thereby providing better transfer of knowledge from departing staff to successors or newly employed so that when a staff leaves, the organization can still survive, that is, documentation and codification of knowledge.

(b) Establish and develop knowledge sharing culture which will help to better organization performance, strengthen working relationships between staff across the organization and concretized a more positive working environment.

(c) It establishes the act of coaching, mentoring and training of new staff on knowledge life cycle process.

(d) It helps an organization to gain competitive advantage over competitors via the reservoir of the knowledge assets and a health level of knowledge asset organization possess by identifying the gap and ineffectiveness and providing workable solutions to present day and futuristic challenges.

(e) Improve the use of external and internal knowledge asset products and services and also the easy retrieval of data, information and knowledge across subunits, department and organization at large.

(f) KA brings customers closer and direct to management or leaders in an organization via social network mapping analysis.

(g) KA bridges the gap between what the organization has and what the organization should project in the future. 
(h) KA helps to measure and account for the knowledge assets created and assist in assessing its value and impact to organizational performance.

(i) It identifies intellectual assets and speed up the building of a corporate knowledge asset register; to separate knowledge assets that are not used to maximize profit and untapped knowledge asset.

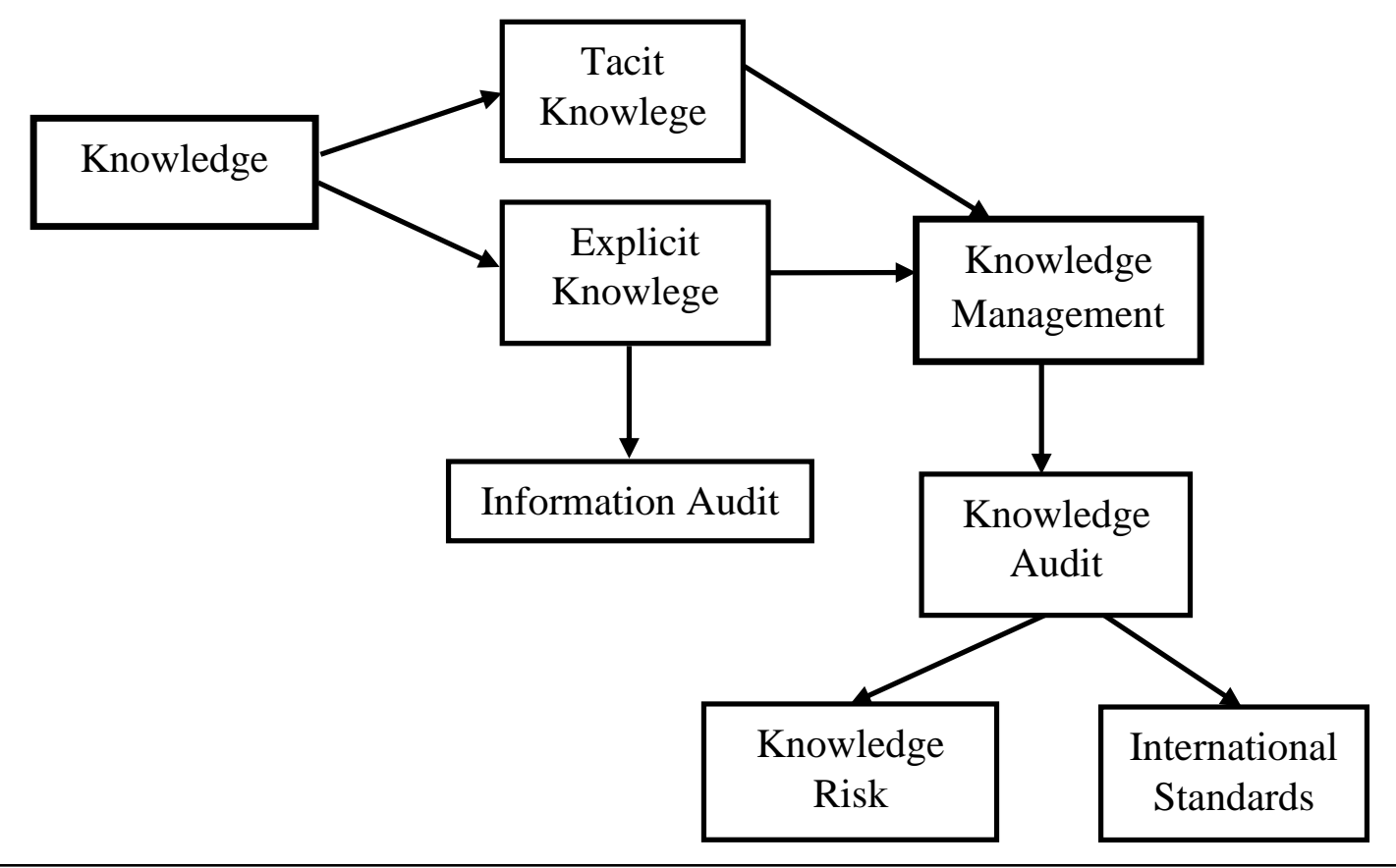

Figure 1: A model showing the relationship between knowledge, knowledge management and knowledge audit by the Authors

\section{Existing KA Methodologies and Framework}

Different methods or framework have been adapted or adopted in the past, as there is no universal framework or method that can be applied to all organization. There should be methods that prescribe specific steps to follow; the methods should specifically engage on knowledge auditing. Hylton (2002) identifies various KA methodologies by identifying and valuating corporate knowledge. He placed more strength on quantity and measuring of human knowledge capital that is existing and in the future.

Cheung et al. (2007) carried out KA of a railway company which eight phases were used; the researchers recommended to the management the creation of organizational culture where employees could share idea, experience and expertise; establish incentive programs to motivate them to add to KM activities, top management support for adoption of KM. Levantakis et al. (2008) proposed a reference method of KA, which was applied to engineering department; which identified four procedures in KA which are defining the outline of the new reference method; activities divided into sub-activities, compare the reference method with existing audit methods, they compared it with Orna (1999), Henczel (2013), Burnett et al. (2013), Perez-Soltero et al., (2006) methods to see similarities and differences; selection of method fragments and assembly of 
the new reference method and the final stage was validation of the KA methods. Also Roberts (2008) carried a KA of a Dutch ICT company, where 58 consultants working on clientele site were located in Netherland which was carried out for two months with the use of questionnaire and interviews. He proposed by comparing/integrating 13 knowledge and information audit methods. They recommend that the organization should be tested in different companies to examine their applicability, adaptability and consistency in all situations, KA activities should be divided in subactivities in order to have a low level view. Roberts (2008) also identified 15 Knowledge element inventory which are needed in organization when conducting KA. These are business strategy, business activities, business processes, outputs, actions, physical/financial capital, human capital, intellectual property, structural capital, professionally managed information activities, internal data, information, intelligence, knowledge resources, external data, information, intelligence, knowledge, Internal and external information delivery, customer capital, external stimuli and environmental factors. The model can be adapted by different business organization to state all the knowledge content indicators. Levy et al. (2010) presents an empirical study that identifies tacit perceptions and cultural barriers that may challenge an organization. The methodology used in this study was knowledge enginnering \& management methods and grounded theory. The researchers suggested that before the design and implementation of a KM solution, there is need to address elicit tacit knowledge and identifying the issues around them. They also suggest strong support from the management for the KM initiative and understanding of culture in the organization before implementation of KM solutions. Therefore, when implementing a KM program will captivate data on tacit knowledge such as belief, value, perceptions and assumptions.

Also, Gourova and Todorova (2010) focused on the phases of KA and shows the concept of an online KA platform developed by Sofia University used to design knowledge portal where KA process was divided into three phases and processes: main preparation phase (KA team, KA plan and KA methodology); actual KA implementation (KA result analysis, KA distribution and KA questionnaire) and the final stage is KA finalization (KA report \& KA roadmap definition). Other researchers proposed knowledge-enabled customer relationship management (KCRM) auditing which was single case study; applied to a paint manufacturing company in UAE, this methodology focused on customer and the essence is to build customer relationship and customer services (Daghfous et al., 2013). The method proposed four steps which are audit initiation, measures and methods selection, audit performance and improvement plan development. The methodology focused on facilitating KCRM approaches in firm. The authors asserted that knowledge moves from high level of tacitness to fully explicit knowledge. The proposed framework integrates and establish strong communication with customers and suppliers. The focus point of Yip et al. (2015) analysis between structured business processes (SBP) and unstructured business processes (UBP) methodologies deployed in KA by bridging the gap which was used to study two companies in Hong Kong. The authors focused on three processes of KA methodologies which are knowledge elicitation, knowledge representation and role of researcher for KA researchers and practitioners. It was stated that departments like maintenance and quality control, production follows more structured business processes while departments like R\&D department and marketing still have areas that are unstructured business processes (UBP).

Shukor et al. (2013) reviewed literature on based on KA on gathering of data techniques, process and KA roles were the keywords on KA, KA process, KA roles and KA outputs were the main target of the literature based on top journals and reputable literatures on KA. It was discovered from the review that all the studies focused on single organization; there is no literature on KA practices for inter-organization. Also, Drus (2020) proposed a KA methodology that is 
suitable for two electricity supply industries in Malaysia; four phases were proposed in the KM methodology which the result is to develop a knowledge strategy which can be adopted as business strategies for electricity companies. The whole methods focus on evalauation, assessment, identification of knowledge, culture, customer relation attributed to KA. All these methods lack the aspect of general standard policies and risk involved in KA.

\section{International and national standards related to $K A$ processes}

The important of knowledge audit is addressed in international and quality standards such as ISO9000, ISO-12207/ ISO-15504. ISO is an international standards and practice for managing organization and used for standardizing practices and continuous improvement in order to meet customers needs. ISO 9001:2015 provide standard quality management system used in organizations, the new ISO 9001:2015 bring out the term 'knowledge' which was not address in ISO 9001 standard. A new clause was added to ISO 9001:2015. The new ISO 9001:2015 addresses knowledge audit in an organization's quality management system to identify present and future challenges in the organization. The benefit of ISO helps to assess the organization objectives and identify new opportunities in business, it puts customers at the heart of business. It increases productivity, efficiency and reduce costs within the organization. It identifies the risks associated with your organization for quality and explains requirements for quality services. It aims at boosting and maintaining customer satisfaction. It addresses requirement for knowledge in organization such as it ensure knowledge are conform with product and services, maintain knowledge, compare the organizational knowledge and future needs, acquire necessary knowledge to meet future needs.

\section{Clause in new ISO 9001:2015 in relation to knowledge audit}

Clause 7.1.6 knowledge: This clause pays enough attention to knowledge to ensure goods and services are of quality in the organization, safeguard the organization from the knowledge loss, encourage knowledge acquisition with the organization via experience, mentorship and benchmarking. It addresses which knowledge is necessary in the organization, knowledge maintained, knowledge available, changes in knowledge, additional knowledge needed in the organization.

Clause 7.2 addresses organization competence, this ensures that staff have competence to perform their duties. The knowledge auditor need to review the KM strategy and ensure that they support acquisition of new knowledge.

Clause 7.5 addresses documented information to ensure quality system. This involves creating, storing, controlling, distributing, accessing, retaining and disposing. The knowledge auditor should distinguish between information and knowledge. The important KA was stressed in the new clause 7.1.5 which stated that organizations should manage, maintain and provide all the knowledge in line with quality standard in order to achieve the organization objective (ISO 9001 Revision, 2015)

SO/IEC/IEEE 90003 is part of ISO 9001:2015 used for software engineering (computer software) guidelines designed for security, maintaining, testing, supplying and developing computer software.

ISO 30491 KMS specifications international standard was published 2018 that houses KMS which is used to manage risks and opportunities in the organization. It also recommended ISO 31000:2018 Risk Management on approaches to knowledge risk (Herdmann, 2020). He 
identifies ISO 30401 and ISO 31000 international standards for managing of knowledge risks. ISO 3100 provides framework and processes for managing risk.

Implementing a KMS in line with ISO 30401:2018 requires top management to establish a KM policy that includes a commitment to manage knowledge enabling the timely creation, maintenance, distribution and access to organizational knowledge required to achieve the organization's objectives.

Knowledge risks are essentially the risks which organizations shall determine according to ISO 30401 clause 6.1 'which need to be addressed to give assurance that the knowledge management system can achieve its objective'. The objective of a knowledge management system is to create, maintain, protect and provide access to knowledge (facts, information, principles or understanding acquired through experience, research or education) necessary to achieve the organizational objectives. The risks that need to be addressed are the typical knowledge risks listed by Durst and Zieba: knowledge loss, knowledge attrition, knowledge leakage.

\section{Sarbanes-Oxley Act (SOX Act, 2002)}

SOX is an international standard used to protect shareholders and all from financial and fraudulent activities in an organization. The main purpose of SOX is to increase transparency, and provide check and balance in financial reporting. It is needed by the financial and IT, knowledge management units; it establishes standards for storing electronic records, how to analyze records that are important to store and the duration of the storage of such information. Organization needs to store all business reports, records and also electronic records for at least five years to meet the SOX requirements (Gupta and Nayar, 2007). Organization implementating SOX will protect their knowledge asset from theft and cyberattacks. It also reduce cyber risks and control, strengthen performance and build a centralized financial reports. The audit examines employee and their job roles so identify similarity and difference; and if they have the required training to safeguard access to financial information by external environment. It audits reports of the internal control, network activities, database activities, login activities, account and user activities and information access. Section 302 and 404 of SOX addresses data management, reporting and security. Section 302 relates.

Christensen (2015) asserted that a research conducted at Protiviti a consulting firm in 2015 for chief officers which age was 45 and above it shows that the organization relies on SOX compliances to run continuous improvement around financial reporting and also there has been an increase of 52 percent of significant improvement in internal control when the execution of SOX.

\section{Knowledge risk and organization}

The Society for Risk Analysis (SRA) had given different definition of risk in the past; which these definitions are tied to event or consequences of uncertainty. The ISO 31000 standard on risk management (ISO 2018), defined risk based on effect of uncertainty on objectives. Therefore, there is need to measure the uncertainty, how uncertainty relates with knowledge. It describes the uncertainty how it relates with the knowledge and also the quality of the knowledge in organization. Present studies shows that there is increasing study in risks in relation to knowledge and intangibles (Durst, 2013; Durst and Zieba, 2018). Tangible and intangibles knowledge risks have more balanced and holistic view on firm's operations and its risk-bearing capacity (Durst and Zieba 2018).

Knowledge is valuable in an organization when 'the right people have and use the right knowledge' (Ilvonen et al., 2015). Knowledge becomes an essential asset, when knowledge from 
its employees gives competitive edge over competitors. However, knowledge might be little valued or even useless when it is not effectively used to achieve the organization objectives. Knowledge is becoming ubitiquous in organizations whereby every organization needs tacit and explicit knowledge to survive. Because knowledge is everywhere, knowledge assets are seen as important assets in the organization, there are a lots of risk involved the creation, processing, storing, archiving, use and re use, updating, retrieving, consulting, sharing and re-sharing and disposing of information. Each of these processes is risky. The organization should identify potential risk issues, analyze the risks using the required skills and right employees; and respond effective to reduce or mitigate against the risk. An organization cannot manage its risk without managing its knowledge (Neef, 2012). There is a synergy between managing knowledge and managing risk which organizations need to work on in order to achieve it organizational objectives because every organization is becoming a knowledge organization. Knowledge management provides a broad framework for managing and controlling data, information and knowledge that existing within and outside the organization. KM explains the process which organizations is collecting, organizing, sharing, disturbing, and learning collectively from staff, board of directors and outside world.

Knowledge risk management (KRM) provide a tool for risk assessment and in response to knowledge in an organization (Kumar, 2020) and knowledge drives the development of technology and socio-economic in our lives (Tsang et al., 2020). Despite these benefits, the applications of knowledge to organization have potentially negative impacts called knowledge risk. When knowledge is mishandled, misused and it has negative effective on the organization is called KR (Trkman and Desouza, 2012; Tsang and Lee, 2018). KR explains the probability of any loss as a result of identifying, creating, storing or protecting of knowledge in an organization which may reduce the operational or strategic advantage of a company (Perrott, 2007) and also KR is a loss from activities with relates to identifying, storage and protection of knowledge applied (Trkman and Desouza, 2012). KM risk can exist in technology and also in human capital (Durst and Zieba, 2019).

There are a lot of risks involved in the use of technology and human capital in organization, the technology aspect of KM are intranet, websites, Enterprise Resource Planning platform, call center technology, customer resource management etc; these are used to capture, process and distribute sensitive information, knowledge about operations of an organization activities in the $\mathrm{KM}$ process which they indicate risk. There is no risk management without good KM. Risk management involves set of processes, activities and systems that allows organization to monitor everyday activities in the organization. The management of a organization needs to know the impact of risk if it is moderate and minor or low, medium and high.

Literature on KR is limited (Durst et al., 2018; Durst and Zieba, 2017; Lee et al., 2014; Massingham, 2010); knowledge auditors need to work on the risk involved in management of knowledge in an organization and identify possible gaps, duplications and provide workable solutions before KM initiative and strategy. Reich (2007) identified five ways which knowledge risks can be managed in IT project which are establishing a learning climate; mitigating knowledge loss, creating channels for knowledge flow; developing a shared team memory and using the risk register to monitor knowledge risks.

Lambe (2013) divided knowledge risk into four which are knowledge continuity risks, knowledge acquisition risks, knowledge outsourcing risks and knowledge articulation risks. He went further to elaborate that knowledge continuity and acquisition risks are key in organization where there is need for evaluation of the knowledge needs of an organization in line with the 
organization objectives and prevent future loss of the knowledge by building a strong learning and experience curve which will accelerate younger employees to take over the core knowledge of old which are needed to achieve the organizational goals. Also, knowledge outsourcing and knowledge articulation risks; the knowledge auditor needs to identify the best practices of outsourcing knowledge; is it better to outsource such knowledge? Will such knowledge if being outsourced not be detrimental to the organization? and will such knowledge not being shared with competitors? Knowledge auditors need to know which parts or departments need to be outsourced and the likelihood of achieving of organizational objectives with outsourcing such knowledge. Knowledge auditor needs to identify core activities, core knowledge assets, opportunities in sharing and retentions of such knowledge and see possible present and future threats in relation to the organizational objectives. Durst and Zieba (2017) also classified KR into internal and external classification. The internal are those $\mathrm{KR}$ inside the organization such as knowledge waste, unlearning and forgetting; knowledge hiding and hoarding while external KR are those outside the organization which are knowledge leakage and knowledge spillover and outsourcing risks.

Durst and Zieba (2018) proposed the division of KR into human, technological and operational. The authors refers Human KR to risk related to a person in an organization, and his social, cultural and psychological factors. Example is hiding knowledge in an organization. Technological KR risk involves risk related to using different technologies and ICT tools to achieve the organization objectives. Example of such risk are risks arise from hacker attack, server lost, epileptic power supply. The rise in the use of ICTs has opened more danger to cyberattack when communicating with different stakeholder. The last one is the operation knowledge risk which is the risk that is involved in day to day activities in an organization such as outsourcing organizational functions or applying old knowledge to business processes. Moreso, the authors opined that organizations should examine knowledge risks because organizational environment are facing a lot of growing complexity and a lot of emerging risks in a knowledge organization. Organization should know that there is an interconnection of knowledge risk whereby one knowledge risk has the likelihood to connect with the other knowledge risk.

\section{The three division of knowledge risk proposed by Durst and Zieba (2018)}

Human knowledge risk can be hiding (Arshad and Ismail, 2018; Cerne et al., 2014; Connelly et al., 2012); hoarding (Holten et al., 2016); unlearning (Cegarra-Navarro et al., 2011; Connelly et al., 2012; Durst and Zieba, 2019), Forgetting (de Holan and Phillips, 2004, 2011; de Holan et al., 2004), Missing/inadequate competencies of organizational members.

Technological risks are Risk related to cybercrime, Risk related to old technologies, digitalization risks, risk related to social media. Operational risks are knowledge waste (Durst and Ferenhof, 2016; Ferenhof et al., 2015), risk related to knowledge gaps (Ferenhof et al., 2015); relational risks (Delerue, 2005; Durst and Ferenhof, 2014); knowledge outsourcing risks (Williams and Durst, 2019), risk of obsolete/unreliable knowledge (Agndal and Nordin, 2009), risk of improper knowledge application, espionage (Chan, 2003; Crane, 2005), continuity risk (Lambe, 2013); communication risks; knowledge acquisition risks; knowledge transfer risk (Tangaraja et al., 2016) merger and acquisition risks. Several authors affirms that knowledge risk could lead to knowledge attrition, knowledge loss (Jennex, 2014), knowledge leakage (Ahmad et al., 2014; Soriano and Parker, 2012), knowledge spillover (Feinberg and Gupta, 2004); and lost reputation (Christopher and Gaudenzi, 2009).

KRM has positive effect on sustainable business in an organization socially, economically, and environmentally (Durst et al., 2019). It was establish that after organization has identified the 
knowledge risks, organization need to take a further assessment on the KR that could affect the organization most and more precisely; the probability that it will occur most and the potential size of the loss need to be identified and analyzed (Durst and Zieba, 2020). Also Handley-Schachler (2020) analyzed four steps used in assessing KRM are knowledge inventory creation; improving learnable knowledge by simplifying of procedures where possible; success planning to that when key persons leave the organization the key knowledge is not lost and lastly far sightness of the knowledge needs in the future. Due to the elementary stage in the field of KRM based on research carried out, there are no well-established models, frameworks and other tools (Durst and Ferenh 2016; Lee et al., 2014; Trkman and Desouza, 2012) to conduct knowledge risk management. An effective tool organization can use is Knowledge audit.

\section{Conclusion}

The study has shown that knowledge is important to drive innovation and create change. It has also highlighted the progress from industrial economy to knowledge economy. The importance of knowledge economy promotes competitiveness within the industry. This study also examines failures of KM initiatives and the need to have effective KA process to curb the failures. Knowledge is an important part in an organization and every organization needs knowledge which can be explicit or tacit knowledge to achieve the organization goals. However, this may be hindered by improper knowledge management. Just as there are various departments in an organization, this paper recommends that there should be knowledge management department which will ensure that knowledge is shared, transferred and utilized for company's growth and development. Knowledge audit being a subset of knowledge management is important to achieve this. Knowledge audit brings about knowledge solution together in order to achieve a holistic solution to knowledge management. KA brings the explicit knowledge which is solved via information audit and tactic knowledge which is solved by knowledge sharing or knowledge risk management. From these, we could deduce that knowledge audit solves the challenges faced in tacit and explicit knowledge to achieve the organizational goals. Knowledge audit is a broad part of information audit. Also KRM has not been effectively explore to fullness. The KA provides the encompassing tools to solve both knowledge challenges in an organization.

The contribution of this work to literature is the area of knowledge risks, andinternational standards that could be applied into KA and also knowledge should be seen as par with other aspects in the organization such physical, staff and financial assets. These are germane to the effective and efficiency of knowledge in an organization. This paper also posits that knowledge is a tangible asset like other factors of production and should be equally valued. Thus, organizations are encouraged to invest in knowledge audit to ensure proper knowledge management within the firm to drive innovation an change.

\section{Limitations and future research}

The study presented invaluable outcomes, however there are limitations that needs to be highlighted. Our study did not present testable propositions due to its focus on a practice approach. This research can further be expanded by providing testable propositions and a theoretical framework. Future research should be on the accounting view of KA with focus on the calculation of profit and loss involved in the knowledge economy to identify its strength and weakness. Also, further research should look into how technology can be leveraged on for knowledge audit. Further research should be on mechanisms used by companies in knowledge audit, and platforms created with organizations for knowledge sharing should be looked into. Studies should be done to 
examine how knowledge audit has promoted effective knowledge management in certain firms. Further research should focus on how international standards contributes to the management of knowledge risk.

\section{References}

Abubakar AM, Elrehail H, Alatailat MA, et al. (2019) Knowledge management, decision-making style and organizational performance. Journal of Innovation \& Knowledge 4(2): 104114.

Abusweilem M, Abualoush S (2019) The impact of knowledge management process and business intelligence on organizational performance. Management Science Letters 9(12): 21432156.

Agndal H, Nordin F (2009) Consequences of outsourcing for organizational capabilities: some experiences from best practice. Benchmarking: An International Journal 16(3): 316-334.

Ahmad A, Bosua R, Scheepers R (2014) Protecting organizational competitive advantage: A knowledge leakage perspective. Computers \& Security 42: 27-39.

Al-Alawi AI, Al-Marzooqi NY, Mohammed YF (2007) Organizational culture and knowledge sharing: critical success factors. Journal of Knowledge Management 11(2): 22-42.

Alavi M, Leidner DE (2001) Knowledge management and knowledge management systems: conceptual foundations and research issues. MIS Quarterly 25: 107-136.

Alhamoudi SA (2010) Strategic knowledge management system in public sector in Saudi Arabia: an adaptation of the balanced scorecard. Unpublished thesis, University of Portsmouth, UK.

Anand A, Walsh I (2016) Should knowledge be shared generously? Tracing insights from past to present and describing a model. Journal of Knowledge Management 20(4): 713-730.

Anantatmula VS, Kanungo S (2010) Modeling enablers for successful KM implementation. Journal of Knowledge Management 14(1): 100-113.

Andreeva T, Sergeeva A (2016) The more the better ... or is it? The contradictory effects of HR practices on knowledge-sharing motivation and behaviour. Human Resource Management Journal 26(2): 151-171.

Aranda DA, Molina-Fernandez LM (2002) Determinants of innovation through a knowledgebased theory lens. Industrial Management \& Data Systems 102(5): 289-296.

Arshad R, Ismail IR (2018) Workplace incivility and knowledge hiding behavior: does personality matter?. Journal of Organizational Effectiveness: People and Performance.

Bou-Llusar CJ, Segarra-Cipres M (2006) Strategic knowledge transfer and its implications for competitive advantage: an integrative conceptual framework. Journal of Knowledge Management 10(4): 100-112.

Braganza A, Mollenkramer GJ (2002) Anatomy of a failed knowledge management initiative: lessons from PharmaCorp's experiences. Knowledge and Process Management 9(1): 2333.

Burnett S, Williams D, Illingworth L (2013) Reconsidering the knowledge audit process: methodological revisions in practice. Knowledge and Process Management 20(3): 141153.

Cegarra-Navarro JG, Sanchez-Vidal ME, Cegarra-Leiva D (2011) Balancing exploration and exploitation of knowledge through an unlearning context. Management Decision 49(7): 1099-1119. 
Cegarra-Navarro JG, Soto-Acosta P, Wensley AK (2016) Structured knowledge processes and firm performance: The role of organizational agility. Journal of Business Research 69(5): 1544-1549.

Černe M, Nerstad CG, Dysvik A, et al. (2014) What goes around comes around: knowledge hiding, perceived motivational climate, and creativity. Academy of Management Journal 57(1): $172-192$.

Chan M (2003) Corporate espionage and workplace trust/distrust. Journal of Business Ethics 42(1): 45-58.

Chang CLH, Lin TC (2015) The role of organizational culture in the knowledge management process. Journal of Knowledge Management 19: 433-455.

Cheung CF, Li ML, Shek WY, et al. (2007) A systematic approach for knowledge auditing: a case study in transportation sector. Journal of Knowledge Management 11(4): 140-158.

Choy SY, Lee WB, Cheung CF (2004) A systematic approach for knowledge audit analysis: integration of knowledge inventory, mapping and knowledge flow analysis. Journal of Universal Computer Science 10(6): 674-682.

Christensen B (2015) Assessing the top priorities for internal audit functions. EDPACS 51(1): 67.

Christopher M, Gaudenzi B (2009) Exploiting knowledge across networks through reputation management. Industrial Marketing Management 38(2): 191-197.

Connelly CE, Zweig D, Webster J, et al. (2012) Knowledge hiding in organizations. Journal of Organizational Behavior 33(1): 64-88.

Costa V, Monteiro S (2016) Key knowledge management processes for innovation: a systematic literature review. VINE: Journal of Information and Knowledge Management Systems 46(3): 386-410.

Crane A (2005) In the company of spies: when competitive intelligence gathering becomes industrial espionage. Business Horizons 48(3): 233-240.

Daghfous A, Ahmad N, Angell LC (2013) The KCRM knowledge audit: model and case illustration. Vine 43(2): 185-209.

Davenport TH, Prusak L (1998) Working knowledge: How organizations manage what they know. Harvard Business Press.

de Holan PM, Phillips N (2004) Organizational forgetting as strategy. Strategic Organization 2(4): 423-433.

de Holan PM, Phillips N (2011) Organizational forgetting. In: Easterby-Smith M, Lyles MA (eds) Handbook of Organizational Learning and Knowledge Management. Hoboken, NJ: John Wiley \& Sons, Inc., pp. 433-451.

de Holan PM, Phillips N, Lawrence TB (2004) Managing organizational forgetting. MIT Sloan Management Review 45(2): 45.

Debenham J, Clark J (1994) The knowledge audit. Robotics and Computer-Integrated Manufacturing 11(3): 201-211.

Delerue H (2005) Relational risk perception and alliance management in French biotechnology SMEs. European Business Review 17(6): 532-546.

Drus SM (2020) Knowledge audit framework: a case study of the Malaysian electricity supply industry. Journal of Information and Communication Technology 16(1): 103-120.

Durst S (2013) An exploratory study of intangibles risk disclosure in annual reports of banking companies from the UK, US, Germany and Italy - some descriptive insights. Financial Reporting 40: 81-120. 
Durst S, Bruns G, Henschel T (2018) The management of knowledge risks: what do we really know? In: Global Business Expansion: Concepts, Methodologies, Tools, and Applications. Hershey, PA: IGI Global, pp. 258-269.

Durst S, Ferenhof HA (2014) Knowledge leakages and ways to reduce them in small and mediumsized enterprises (SMEs). Information 5(3): 440-450.

Durst S, Ferenhof HA (2016) Knowledge risk management in turbulent times. In: North K, Varvakis G (eds) Competitive Strategies for Small and Medium Enterprises. Cham: Springer, pp. 195-209.

Durst S, Hinteregger C, Zieba M (2019) The linkage between knowledge risk management and organizational performance. Journal of Business Research 105: 1-10.

Durst S, Zieba M (2017) Knowledge risks - towards a taxonomy. International Journal of Business Environment 9(1): 51-63.

Durst S, Zieba M (2018) Knowledge risks in the sharing economy. In: Knowledge Management in the Sharing Economy. Cham: Springer, pp. 253-270.

Durst S, Zieba M (2019) Mapping knowledge risks: towards a better understanding of knowledge management. Knowledge Management Research \& Practice 17(1): 1-13.

Durst S, Zieba M (2020) Knowledge risks inherent in business sustainability. Journal of Cleaner Production 251: 119670.

El-Farr H, Hosseingholizadeh R (2019) Aligning human resource management with knowledge management for better organizational performance: how human resource practices support knowledge management strategies? In: Current Issues in Knowledge Management. London: IntechOpen.

Elhachemi T (2020) The influence of knowledge management practice on knowledge acquisition: conceptual paper proposition. Journal of Global Business and Social Entrepreneurship 6(17): 1-9.

Feinberg SE, Gupta AK (2004) Knowledge spillovers and the assignment of R\&D responsibilities to foreign subsidiaries. Strategic Management Journal 25(8-9): 823-845.

Ferenhof H, Durst S, Selig P (2015) Knowledge waste in organizations: a review of previous studies. Brazilian Journal of Operations \& Production Management 12(1): 160-178.

Gold AH, Malhotra A, Segars AH (2001) Knowledge management: an organizational capabilities perspective. Journal of Management Information Systems 18(1): 185-214.

Gourlay S (2002) Tacit knowledge, tacit knowing, or behaving? In: 3rd European Organizational Knowledge, Learning and Capabilities Conference, Athens, Greece, 5-6 April 2002, pp. $1-24$.

Gourova E, Antonova A, Todorova Y (2009) Knowledge audit concepts, processes and practice. Wseas Transactions on Business and Economics 6(12): 605-619.

Gourova E, Todorova Y (2010, July) Knowledge audit data gathering and analysis. In: Proceedings of the 15th European Conference on Pattern Languages of Programs, pp. $1-7$.

Gupta PP, Nayar N (2007) Information content of control deficiency disclosures under the Sarbanes-Oxley Act: an empirical investigation. International Journal of Disclosure and Governance 4(1): 3-23.

Handley-Schachler M (2020) Port knowledge risk management. In: Durst S, Henschel T (eds) Knowledge Risk Management. Cham: Springer, pp. 185-206. Henczel S (2001) The information audit as a first step towards effective knowledge management. Information Outlook 5(6): 13. 
Henczel S (2013) The Information Audit: A Practical Guide. Berlin: Walter de Gruyter. Herdmann F (2020) Handling knowledge risk management supported by ISO standards. In: Knowledge Risk Management. Cham: Springer, pp. 229-251.

Holten AL, Hancock GR, Persson R, et al. (2016) Knowledge hoarding: antecedent or consequent of negative acts? The mediating role of trust and justice. Journal of Knowledge Management 20(2): 215-229.

Hylton A (2002a) Measuring \& Assessing Knowledge-Value \& the Pivotal Role of the Knowledge Audit. London: Hylton Associates.

Hylton A (2002b) Measuring \& Assessing Knowledge-Value \& the Pivotal Role of the Knowledge Audit. London: Hylton Associates.

Ilvonen I, Jussila JJ, Kärkkäinen H (2015) Towards a business-driven process model for knowledge security risk management: making sense of knowledge risks. International Journal of Knowledge Management (IJKM) 11(4): 1-18.

ISO 30400:2016 (2016) Human Resource Management - Vocabulary. Geneva:

ISO 30401:2018 (2018) Knowledge Management Systems - Requirements. Geneva: ISO.

ISO 31000:2018 (2018) Risk Management - Guidelines. Geneva:

Jennex M, Olfman L (2005) Assessing knowledge management success. International Journal of Knowledge Management (IJKM) 1(2): 33-49.

Jennex ME (2014) A proposed method for assessing knowledge loss risk with departing personnel. VINE: Journal of Information and Knowledge Management Systems 44(2): 185-209.

Kaniki AM, Mphahlele MK (2002) Indigenous knowledge for the benefit of all: can knowledge management principles be used effectively? South African Journal of Libraries and Information Science 68(1): 1-15.

Kianto A, Andreeva T (2014) Knowledge management practices and results in service-oriented versus product-oriented companies. Knowledge and Process Management 21(4): 221230.

Kianto A, Hussinki H, Vanhala M (2018) The impact of knowledge management on the market performance of companies. In: Vatamanescu EM, Pinzaru FM (eds) Knowledge Management in the Sharing Economy. Cham: Springer, pp. 189-207.

Kianto A, Shujahat M, Hussain S, et al. (2019) The impact of knowledge management on knowledge worker productivity. Baltic Journal of Management 14(2): 178-197.

Kumar S (2020) Knowledge risk management for state-owned enterprises - Indian scenario. In: Durst S, Henschel T (eds) Knowledge Risk Management. Cham: Springer, pp. 89-106.

LaFayette B, Curtis W, Bedford D, et al. (2019) How the Knowledge Economy Works. Knowledge Economies and Knowledge Work (Working Methods for Knowledge Management). Bingley: Emerald Publishing Limited, pp. 17-39.

Lambe P (2013) Four types of knowledge risk. Available at: http://www.greenchameleon.com/uploads/Four_Types_of__ Knowledge_Risk.pdf (accessed 24 May 2020).

Lateef A, Omotayo FO (2019) Information audit as an important tool in organizational management: A review of literature. Business Information Review 36(1): 15-22.

Lee H, Choi B (2003) Knowledge management enablers, processes, and organizational performance: an integrative view and empirical examination. Journal of Management Information Systems 20(1): 179-228.

Lee S, Suh E, Lee M (2014) Measuring the risk of knowledge drain in communities of practice. Journal of Knowledge Management 18(2): 382-395. 
Leidner D, Alavi M, Kayworth T (2006) The role of culture in knowledge management: a case study of two global firms. International Journal of e-Collaboration 29(1): 17-40.

Levallet N, Chan YE (2016) Knowledge loss and retention: the paradoxical role of IT. In: Successes and Failures of Knowledge Management. Burlington, MA: Morgan Kaufmann, pp. 97-111.

Levantakis D, Helms R, Spruit M (2008) Developing corporate taxonomies for knowledge auditability - a framework for good practices. Journal of Knowledge Organization 35(1). Available at: SSRNhttps://ssrn.com/abstract1/41258162 (accessed 14 May 2020).

Levy M, Hadar I, Greenspan S, et al. (2010) Uncovering cultural perceptions and barriers during knowledge audit. Journal of Knowledge Management 14(1): 114-127.

Liebowitz J (2001) Knowledge management and its link to artificial intelligence. Expert Systems with Applications 20(1): 1-6.

Liebowitz J (2016) Successes and Failures of Knowledge Management. Burlington, MA: Morgan Kaufmann.

Liebowitz J, Montano B, McCaw D, et al. (2000) The knowledge audit. Knowledge and Process Management 7(1): 3-10.

Lin HF (2007) A stage model of knowledge management: an empirical investigation of process and effectiveness. Journal of Information Science 33(6): 643-659.

Lytras MD, Athanasia P, Angeliki P (2002) Knowledge management convergence - expanding learning frontiers. Journal of Knowledge Management 6(1): 40-51.

Malhotra Y (2003) Measuring knowledge assets of a nation: knowledge systems for development. In: Invited Research Paper Sponsored by the United Nations Department of Economic and Social Affairs. Keynote Presentation at the Ad Hoc Group of Experts Meeting at the United Nations Headquarters, New York City, NY, pp. 4-5.

Marwick AD (2001) Knowledge management technology. IBM Systems Journal 40(4): 814-830.

Massingham P (2010) Knowledge risk management: a framework. Journal of Knowledge Management 14(3): 464-485.

Mearns MA, Du Toit ASA (2008) Knowledge audit: tools of the trade transmitted to tools for tradition. International Journal of Information Management 28: 161-167.

Meher JR, Mishra RK (2019) Accessing the influence of knowledge management practices on organizational performance; an ISM approach. VINE: Journal of Information and Knowledge Management Systems 49(3): 440-456.

Metaxiotis K, Ergazakis K, Psarras J, et al. (2005) Exploring the world of knowledge management: agreement and disagreement in the academic/practitioner community. Journal of Knowledge Management 9(2): 6-18.

Neef D (2012) Managing Corporate Reputation and Risk. London: Routledge.

Newell S, Tansley C, Huang J (2004) Social capital and knowledge integration in an ERP project team: the importance of bridging and bonding. British Journal of Management 15(S1): 43-57.

Nisula AM, Kianto A, Andreeva T (2019) What can knowledge-creating organisations learn from theatrical improvisation? In: Handzic M, Carlucci D (eds) Knowledge Management, Arts, and Humanities. Cham: Springer, pp. 55-75.

Nonaka I (1991) The knowledge creating company. Harvard Business Review 69: 96-104.

Nonaka I, Peltokorpi V (2006) Objectivity and subjectivity in knowledge management: a review of 20 top articles. Knowledge and Process Management 13(2): 73-82. 
Nonaka I, Takeuchi H (1995) The Knowledge-Creating Company: How Japanese Companies Create the Dynamics of Innovation. New York, NY: Oxford University Press.

Orna E (1999) Practical Information Policies. Aldershot: Gower Publishing, Ltd.

Perez-Soltero A, Barcelo-Valenzuela M, Sanchez-Schmitz G, et al. (2006, July) Knowledge audit methodology with emphasis on core processes. In: European and Mediterranean Conference on Information Systems, Costa Blanca, Alicante, Spain, 6-7 July 2006, pp. $1-10$.

Perrott BE (2007) A strategic risk approach to knowledge management. Business Horizons 50(6): 523-533.

Reich BH (2007) Managing knowledge and learning in IT projects - a conceptual framework and guidelines for practice. Project Management Journal 38(2): 5-17.

Ringel-Bickelmaier C, Ringel M (2010) Knowledge management in international organisations. Journal of Knowledge Management 14(4): 524-539.

Roberts SA (2008) Recording knowledge-related activities in practice. Aslib Proceedings 60(6): 583-599.

Rozman M, Shmeleva Z, Tominc P (2019) Knowledge management components and their impact on work engagement of employees. Nase Gospodarstvo/Our Economy 65(1): 40-56.

Ruggles R (1998) The state of the notion: knowledge management in practice. California Management Review 40(3): 80-89.

Serrat O (2017) Knowledge Solutions: Tools, Methods, and Approaches to Drive Organizational Performance. London: Springer Nature, pp. 1140.

Shropshire S, Semenza JL, Koury R (2019) Knowledge management in practice in academic libraries. International Federation of Library Associations and Institutions 20(10): 1-9.

Shukor NSA, Rahman AA, Iahad NA (2013) A review on knowledge audit process. In: PACIS, Malaysia, 2013, p. 256.

Soriano DR, Parker H (2012) Knowledge acquisition and leakage in inter-firm relationships involving new technology-based firms. Management Decision 50(9): 1618-1633.

Storey J, Barnett E (2000) Knowledge management initiatives: learning from failure. Journal of Knowledge Management 4: 145-156.

Susanty AI, Yuningsih Y, Anggadwita G (2018) Knowledge management practices and innovation performance: a study at Indonesian Government apparatus research and training center. Journal of Science and Technology Policy Management 10(2): 301-318.

Tangaraja G, Rasdi RM, Samah BA, et al. (2016) Knowledge sharing is knowledge transfer: a misconception in the literature. Journal of Knowledge Management.

Temel S, Vanhaverbeke W (2020) Knowledge risk management during implementation of open innovation. In: Durst S, Henschel T (eds) Knowledge Risk Management. Cham: Springer, pp. 207-227.

Tiwana A (2002) The knowledge management toolkit: practical techniques for building a knowledge management system with cdrom.

Trkman P, Desouza KC (2012) Knowledge risks in organizational networks: An exploratory framework. The Journal of Strategic Information Systems 21(1): 1-17.

Tsang HWC, Lee RW (2018) Mitigation of knowledge risks in open innovation. Open Innovation and Knowledge Management in Small and Medium Enterprises, pp. 183-203.

Tsang HWC, Lee WB, Tsui E (2020) AHP-driven knowledge leakage risk assessment model: a construct-apply-control cycle approach. In: Start-Ups and SMEs: Concepts, Methodologies, Tools, and Applications. Hershey, PA: IGI Global, pp. 218-237. 
Wamuyu PK, Ndiege JR (2018) Conceptualisation of a knowledge management framework for government: a case of devolved county governments in Kenya. In: 2018 Thirteenth International Conference on Digital Information Management (ICDIM), Berlin, Germany, 24-26 September 2018, pp. 266-273. IEEE.

Williams C, Durst S (2019) Exploring the transition phase in offshore outsourcing: Decision making amidst knowledge at risk. Journal of Business Research 103: 460-471.

Wu YL, Li YH (2008, October) Research on the model of knowledge audit. In: 2008 4th International Conference on Wireless Communications, Networking and Mobile Computing, pp. 1-4. IEEE.

Yeh YJ, Lai SQ, Ho CT (2006) Knowledge management enablers: a case study. Industrial Management \& Data Systems 106(6): 793-810.

Yip JY, Lee RW, Tsui E (2015) Examining knowledge audit for structured and unstructured business processes: a comparative study in two Hong Kong companies. Journal of Knowledge Management 19(3): 514-529. 